\section{Facharztprüfung zur Erlangung des Facharzttitels FMH für Pharmazeutische Medizin}

Aufgrund des Weiterbildungsprogrammes, welches am 1. Januar 1999 in Kraft gesetzt wurde, ist die Teilnahme an der Facharztprüfung für diejenigen Kandidatinnen und Kandidaten Voraussetzung für die Erlangung des Facharzttitels FMH für Pharmazeutische Medizin, welche ihre Weiterbildung in Pharmazeutischer Medizin am 31. Dezember 2000 nicht abgeschlossen hatten. Es empfiehlt sich, die Facharztprüfung frühestens im letzten Jahr der reglementarischen Weiterbildung abzulegen (Art. 22 WBO).
Ort: Basel, der genaue Ort wird später mitgeteilt.

Datum: Die Prüfung besteht aus einem schriftlichen und einem mündlichen Teil. Das Bestehen der schriftlichen Prüfung ist Voraussetzung zur Teilnahme an der mündlichen Prüfung.

- Schriftliche Prüfung: 12. Juli 2001

- Praktische Prüfung: 23. August 2001

Prüfungsgebühr: Die SGPM erhebt eine Prüfungsgebühr von Fr. 700.- für Mitglieder und 1200.- für Nichtmitglieder der SGPM.

Anmeldung: Schriftliche Anmeldung unter Beilage des Weiterbildungscurriculums an den Präsidenten der Prüfungskommission: Dr. med. Beat Althaus, GlaxoSmithKline, Bahnhofstrasse 5, 3322 Schönbühl.

Anmeldefrist: 31. Mai 2001

\section{Examen de spécialiste en vue de l'obtention du titre FMH en médecine pharmaceutique}

Conformément au programme de formation postgraduée qui est entré en vigueur le $1^{\text {er }}$ janvier 1999, la participation à l'examen de spécialiste est obligatoire pour les candidats à l'obtention du titre FMH en médecine pharmaceutique qui n'avaient pas terminé leur formation postgraduée en médecine pharmaceutique le 31 décembre 2000. Il est recommandé de passer l'examen de spécialiste au plus tôt durant la dernière année de formation postgraduée réglementaire (art. 22 RFP).
Lieu: Bâle, le lieu exact sera communiqué ultérieurement.

Date: L'examen comporte une partie écrite et une partie orale. Seuls les candidats ayant réussi la partie écrite de l'examen sont admis à la partie orale.

- Examen écrit: 12 juillet 2001

- Examen oral: 23 août 2001

Taxe d'examen: La SSMP prélève une taxe d'examen de Fr. 700.- pour les membres et de 1200.- pour les non-membres de SSMP.

Inscription: à adresser par écrit en associant un curriculum de formation au président de la commission d'examen: Dr Beat Althaus, GlaxoSmithKline, Bahnhofstrasse 5, 3322 Schönbühl.

Délai d'inscription: 31 mai 2001 